\title{
MicroRNA-433 inhibits cervical cancer progression by directly targeting metadherin to regulate the AKT and $\beta$-catenin signalling pathways
}

\author{
CHANGYAN LIANG* ${ }^{*}$ JIE DING* ${ }^{*}$ YUEBO YANG, LIUZHI DENG and XIAOMAO LI \\ Department of Gynecology, The Third Affiliated Hospital of Sun Yat-sen University, \\ Guangzhou, Guangdong 510630, P.R. China
}

Received April 20, 2017; Accepted September 28, 2017

DOI: $10.3892 /$ or.2017.6049

\begin{abstract}
Cervical cancer is one of the most common female malignancies worldwide. Emerging data have shown that microRNAs (miRNAs) play significant roles in various human cancers, including cervical cancer. Aberrantly expressed miRNAs in cervical cancer contribute to tumour occurrence and development as either tumour suppressors or promoters. Research suggests that miRNA-433 (miR-433) possibly plays an important role in the development of various cancer types. However, no study has explored the expression patterns, roles and underlying mechanisms of miR-433 in cervical cancer. In the present study, we demonstrated significant downregulation of miR-433 in cervical cancer tissues and cell lines. Low miR-433 expression was found to significantly correlate with patient characteristics including tumour size, International Federation of Gynecology and Obstetrics stage, lymph node and distant metastases. Functional studies showed that restoration of miR-433 inhibited cell proliferation and invasion and increased apoptosis in cervical cancer cells. Metadherin $(M T D H)$ was also validated as a direct target gene of miR-433. $M T D H$ mRNA expression was upregulated in cervical cancer tissues and was inversely correlated with miR-433 expression. MTDH knockdown showed similar tumour-suppressive roles as miR-433 overexpression in regards to cervical cancer cell proliferation, invasion and apoptosis. Rescue experiments revealed that $M T D H$ overexpression markedly reversed the effects of miR-433 overexpression in regards to proliferation, invasion and apoptosis of cervical cancer cells. Further investigations revealed that miR-433 inactivated AKT and $\beta$-catenin
\end{abstract}

Correspondence to: Professor Xiaomao $\mathrm{Li}$, Department of Gynecology, The Third Affiliated Hospital of Sun Yat-sen University, 600 Tian He Road, Guangzhou, Guangdong 510630, P.R. China

E-mail: tigerlee2017@sina.com

${ }^{*}$ Contributed equally

Key words: cervical cancer, microRNA-433, metadherin, AKT, $\beta$-catenin pathways in cervical cancer. Collectively, these findings indicate the essential roles of miR-433 in suppressing cervical cancer progression and suggest its potential as a therapeutic target for the treatment of cervical cancer.

\section{Introduction}

With an estimated 500,000 new cases and 300,000 deaths per year, cervical cancer is one of the most common female malignancies worldwide (1). Approximately $80 \%$ of cases occur in developing countries, where extensive screening by cervical cytology is unavailable (2). Cervical cancer morbidity is low in developed countries due to available cervical screening and ongoing active health education programs (3). Currently, several therapeutic strategies, including surgery, chemotherapy and radiotherapy, are utilised to treat patients with cervical cancer $(4,5)$. Although tremendous advances have been made in conventional treatments, the prognosis of cervical cancer remains poor due to development of resistance to radiotherapy and chemotherapy (6). The overall 5-year survival rate is $<40 \%$, particularly for patients presenting with advanced stage disease (7). Therefore, identification of the mechanisms underlying the formation and progression of cervical cancer may significantly promote early diagnosis, prognosis and development of novel therapeutic methods for patients with this malignancy.

Numerous studies have reported that abnormal expression of microRNAs (miRNAs) is significantly involved in the pathogenesis of human cancers, including cervical cancer (8-10). miRNAs comprise a large group of small and endogenous RNAs measuring 18-23 nucleotides in length and are unable to encode for proteins (11). miRNAs can modulate expression of their target genes by binding to target mRNAs at the 3'-untranslated region (3'-UTR), forming stable duplexes in a partial complementary manner and inducing mRNA degradation or interfering with translation (12). Through these regulatory roles, miRNAs play key roles in many cellular biological processes, such as cellular development, growth, differentiation, epithelial-mesenchymal transition and apoptosis (13). In recent years, a wide variety of miRNAs were discovered to be abnormally expressed in various types of human cancer, such as breast (14), lung (15), prostate (16), 
cervical (17) and ovarian cancer (18). Accumulated evidence also suggests that miRNA dysregulation contributes to initiation and progression of various human malignancies (19-21). In human cancer, miRNAs may function as oncogenes by inhibiting tumour-suppressor genes or as tumour suppressors by downregulating oncogenes $(22,23)$. Therefore, miRNA regulation may be a potential therapeutic strategy for human cancer treatment.

miRNA-433 (miR-433) has been studied in several types of human cancer (24-26). However, little information is available concerning the expression pattern and biological roles of miR-433 in cervical cancer. In the present study, we investigated the miR-433 expression pattern in cervical cancer, the effects of miR-433 on cervical cancer cells and the underlying molecular mechanisms. Metadherin $(M T D H)$ (also known as $A E G-1$ or $L Y R I C$ ) was predicted as a potential target of miR-433 and was selected for further target identification; this gene is upregulated in cervical cancer tissues and contributes to cervical cancer occurrence and progression $(27,28)$. The present study may provide novel insights into cervical cancer initiation and progression and strategies for cervical cancer treatment.

\section{Materials and methods}

Ethics statement and tissue samples. The present study was performed according to the principles of the Declaration of Helsinki and approved by the Ethics Committees of The Third Affiliated Hospital of Sun Yat-Sen University. Written informed consent for research purposes was also provided by each participant. Cervical cancer tissues and corresponding adjacent normal tissues were collected from 65 patients who underwent surgical resection at The Third Affiliated Hospital of Sun Yat-sen University between September 2014 and January 2016. All the patients did not receive prior radiotherapy or chemotherapy. All tissue samples were stored in liquid nitrogen until use.

Cell lines. Cervical cancer cell lines (HeLa, C-33A, SiHa and $\mathrm{Ca}-\mathrm{Ski}$ ) and a human normal cervical epithelial cell line (Ect1/E6E7) were purchased from the American Type Culture Collection (ATCC; Manassas, VA, USA). Cervical cancer cells were grown in Dulbecco's modified Eagle's medium (DMEM) supplemented with $10 \%$ fetal bovine serum (FBS), $100 \mathrm{IU} / \mathrm{ml}$ penicillin and $100 \mu \mathrm{g} / \mathrm{ml}$ streptomycin (Gibco, Grand Island, NY, USA). Ect1/E6E7 cells were maintained in keratinocyte serum-free medium (Gibco) containing $0.1 \mathrm{ng} / \mathrm{ml}$ human recombinant epithelial growth factor, $0.05 \mathrm{mg} / \mathrm{ml}$ bovine pituitary extract, $100 \mathrm{IU} / \mathrm{ml}$ penicillin, and $100 \mu \mathrm{g} / \mathrm{ml}$ streptomycin (Gibco) at $37^{\circ} \mathrm{C}$ in a humidified incubator with $5 \% \mathrm{CO}_{2}$.

Cell transfection. The miR-433 mimics and negative control miRNA mimics (miR-NC) were obtained from GeneCopoeia (Guangzhou, China). MTDH-targeted small interfering RNA (si-MTDH) and the negative control siRNA (si-NC) were chemically synthesized by GenePharma Co., Ltd. (Shanghai, China). MTDH overexpressed vector (pCDNA3.1-MTDH) and corresponding blank vector (pCDNA3.1) were obtained from the Chinese Academy of Sciences (Changchun, China). Cells were seeded into 6-well plates $18-24 \mathrm{~h}$ before transfection.
Table I. RT-qPCR primers.

\begin{tabular}{lll}
\hline Gene & & \multicolumn{2}{c}{ Sequences $\left(5^{\prime} \rightarrow 3^{\prime}\right)$} \\
\hline MicroRNA-433 & F & TGCGGTACGGTGAGCCTGTC \\
& R & CCAGTGCAGGGTCCGAGGT \\
U6 & F & CTTCAAGTAATCCAGGATAGGC \\
& R & ATTGGAACGATACAGAGAAGATT \\
MTDH & F & TGCCTCCTTCACAGACCAA \\
& R & TCGGCTGCAGATGAGATAG \\
GAPDH & F & CATGAGAAGTATGACAACAGCCT \\
& R & AGTCCTTCCACGATACCAAAGT
\end{tabular}

F, forward; R, reverse; MTDH, metadherin.

Following the protocols for the use of Lipofectamine 2000 (Invitrogen, Carlsbad, CA, USA), miR-433 mimics (60 nM), miR-NC $(60 \mathrm{nM})$, si-MTDH $(60 \mathrm{nM})$, si-NC $(60 \mathrm{nM})$, pcDNA3.1-MTDH $(2 \mathrm{mg} / \mathrm{ml})$ or pcDNA3.1 $(2 \mathrm{mg} / \mathrm{ml})$ was transfected into the cells. After incubation for $6 \mathrm{~h}$, the culture medium was replaced with fresh DMEM with $10 \%$ FBS. Reverse transcription-quantitative polymerase chain reaction (RT-qPCR) and western blotting were performed to determine the transfection efficiency.

$R T-q P C R$. Total RNA was isolated from tissue samples or cells using TRIzol (Thermo Fisher Scientific, Waltham, MA, USA) according to the manufacturer's instructions. For miR-433 expression, reverse transcription was performed using TaqMan MicroRNA Reverse Transcription kit (Applied Biosystems, Foster City, CA, USA). Quantitative PCR was performed to detect the miR-433 expression level using TaqMan MicroRNA PCR kit (Applied Biosystems). To quantify MTDH mRNA expression, PrimeScript RT reagent kit was used to synthesize cDNA, which was then amplified using SYBR Premix Ex $\mathrm{Taq}^{\mathrm{TM}}$ kit (both from Takara Bio, Dalian, China). GAPDH and U6 were used for normalization of $M T D H$ mRNA and miR-433, respectively. Primers used in the present study were purchased from Guangzhou RiboBio Co., Ltd. (Guangzhou, China) and shown in Table I. Each sample was performed in triplicate, and relative expression changes were calculated using the $2^{-\Delta \Delta \mathrm{Ct}}$ method (29).

MTT assay. Cell proliferation was determined using the MTT assay (Sigma, St. Louis, MO, USA). At $24 \mathrm{~h}$ post-transfection, transfected cells were collected and seeded into 96-well plates at a density of $3.0 \times 10^{3} /$ well. The plates were incubated for 0 , 24,48 or $72 \mathrm{~h}$ after transfection. At each time point, cells were treated with $20 \mu \mathrm{l}$ MTT assay reagent $(5 \mathrm{mg} / \mathrm{ml})$ for additional $4 \mathrm{~h}$. The supernatant was removed, and $150 \mu \mathrm{l}$ of dimethyl sulfoxide (Sigma) was added into each well. Cellular proliferation was determined by detecting the optical density (OD) at a wavelength of $490 \mathrm{~nm}$. Each assay was performed in triplicate and repeated 3 times.

Cell invasion assay. The Matrigel invasion chambers were utilized to assess cell invasion ability $(8 \mu \mathrm{m}$; Corning, 

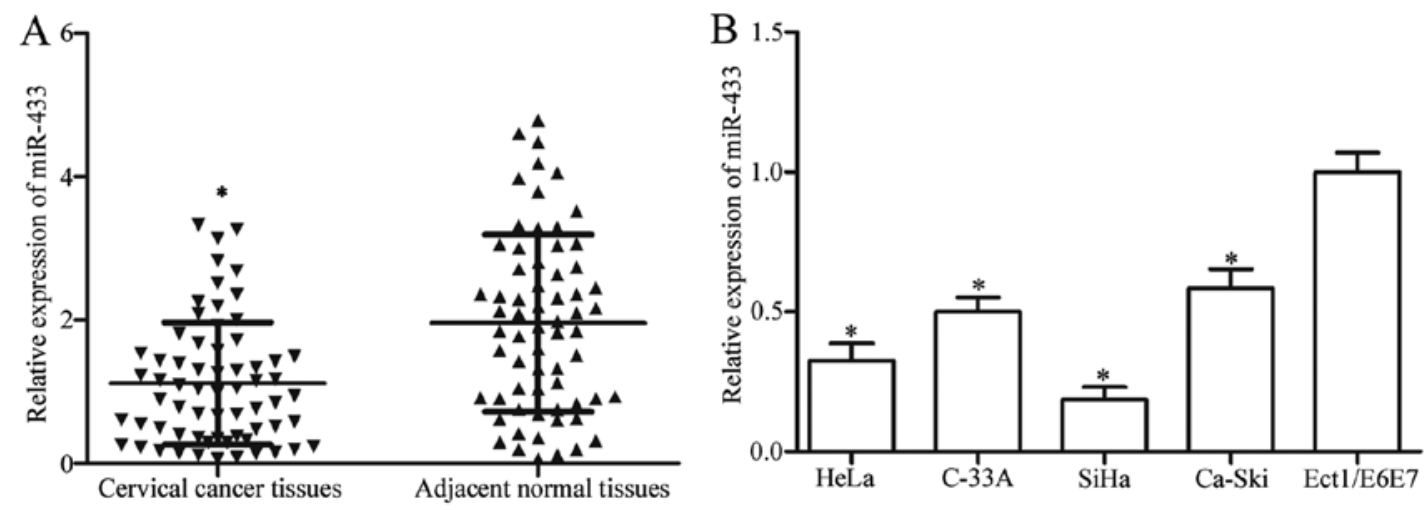

Figure 1. Expression of miR-433 is downregulated in cervical cancer tissues and cell lines. (A) Relative expression of miR-433 in 65 paired cervical cancer tissues and corresponding adjacent normal tissues, as assessed by RT-qPCR. (B) Expression level of miR-433 in 4 cervical cancer cell lines (HeLa, C-33A, $\mathrm{SiHa}$ and Ca-Ski) and human normal cervical epithelial cell line (Ect1/E6E7); $\mathrm{P}<0.05$, compared with the Ect1/E6E7 cells.

Cambridge, MA, USA). At $48 \mathrm{~h}$ post-transfection, cells were incubated with FBS-free culture medium. On the following day, cells were harvested and suspended in FBS-free culture medium. Cells $\left(1 \times 10^{5}\right)$ were placed intothe upper chambers, and the lower chambers were filled with DMEM containing $10 \%$ FBS. After incubation for $48 \mathrm{~h}$, the cells remaining on the top of the chambers were removed. Cells that invaded to the bottom of the membranes were fixed, stained with $0.5 \%$ crystal violet and washed. The invasive cells in at least 5 randomly selected fields were photographed and counted under an inverted microscope (Olympus Corp., Tokyo, Japan). The present study was performed in triplicate and repeated 3 times.

Flow cytometric analysis. The cell apoptosis rate was determined using the Dead Cell Apoptosis Kit with Annexin V Alexa Fluor $^{\mathrm{TM}} 488$ and propidium iodide (PI) (catalog no. V13241; Thermo Fisher Scientific, Waltham, MA, USA), according to the manufacturer's instructions. Subsequent to a 72-h incubation, transfected cells were harvested. After washing 3 times with ice-cold phosphate-buffered saline (PBS), the transfected cells were fixed in $80 \%$ ice-cold ethanol in PBS. Subsequently, the cells were resuspended in $100 \mu \mathrm{l}$ Annexin-binding buffer and incubated with $5 \mu \mathrm{l}$ Annexin V-FITC and $3 \mu \mathrm{l}$ PI (50 $\mu \mathrm{g} /$ $\mathrm{ml}$ ). After incubation at room temperature in the dark for $20 \mathrm{~min}$, cell apoptosis was examined using flow cytometry and analyzed using FACSCalibur and CellQuest software (Beckman Coulter, Inc., Miami, FL, USA).

Bioinformatic predication. TargetScan (http://www. targetscan.org/index. html) and miRanda (http://www. microrna.org/microrna/) were adopted to analyze the potential targets of miR-433 (30). 'Human' was selected as the species, and 'miR-433' was entered. Putative miRNA-mRNA interaction was based on the total context score. The more negative the total context score, the higher the probability of miRNAmRNA binding. Relevant targets predicted by all 2 databases were chosen for laboratory experimentation.

Luciferase reporter assay. Luciferase reporter plasmids, pMIR-Report-MTDH-3'-UTR-wild-type (Wt) and pMIRReport-MTDH-3'-UTR-mutant (Mut), were synthesized and confirmed by GenePharma. Cervical cancer cells were co-transfected with pMIR-Report-MTDH-3'-UTR-Wt or pMIR-Report-MTDH-3'-UTR-Mut and miR-433 mimics or miR-NC using Lipofectamine 2000. After incubation for $48 \mathrm{~h}$, luciferase reporter assays were conducted using the Dual-Luciferase Reporter Assay System (Promega, Madison, WI, USA) following the manufacturer's instructions. Firefly luciferase activity was used as an internal control for Renilla luciferase activity. All experiments were carried out in triplicate and repeated 3 times.

Western blot analysis. Total cell lysates were prepared by incubating cells in RIPA buffer (Beyotime, Shanghai, China) on ice for $1 \mathrm{~h}$. The concentration of protein was determined using the BCA protein assay kit according to the manufacturer's protocol (Pierce Biotechnology, Inc., Rockford, IL, USA). Equal amounts of proteins were separated on $10 \%$ sodium dodecyl sulfate-polyacrylamide gel electrophoresis gels, transferred onto polyvinylidene difluoride membranes (Millipore, Billerica, MA, USA), blocked with 5\% skim milk in Tris-buffered saline containing $0.05 \%$ Tween-20 (TBST), and incubated with primary antibodies overnight at $4^{\circ} \mathrm{C}$ as follows: mouse anti-human monoclonal MTDH (sc-517220; 1:1,000 dilution), mouse anti-human monoclonal p-AKT (sc-271966; 1:1,000 dilution), mouse anti-human monoclonal AKT (sc-56878; 1:1,000 dilution), rabbit anti-human monoclonal p- $\beta$-catenin (ab75777; 1:1,000 dilution) (all from Santa Cruz Biotechnology, Santa Cruz, CA, USA), mouse anti-human monoclonal $\beta$-catenin antibody (ab22656; Abcam, Cambridge, UK, USA), and mouse anti-human monoclonal GAPDH (sc-32233; 1:1,000 dilution; Santa Cruz Biotechnology). In the following steps, membranes were washed with TBST and probed with corresponding horseradish peroxidase (HRP)-conjugated secondary antibody (1:5,000 dilution; Santa Cruz Biotechnology) for $2 \mathrm{~h}$ at room temperature. The protein bands were detected using enhanced chemiluminescence (ECL) solution (Pierce Biotechnology, Inc.). GAPDH was used as an internal control.

Statistical analysis. All data are expressed as mean \pm SD, and were compared with two-tailed Student's t-test or one way ANOVA using SPSS 19.0 statistical software (SPSS, 
Table II. Correlations between miR-433 expression and the clinicopathologic features of the cervical cancer cases.

\begin{tabular}{|c|c|c|c|c|}
\hline \multirow[b]{2}{*}{ Features } & \multirow{2}{*}{$\begin{array}{l}\text { No. of } \\
\text { cases }\end{array}$} & \multicolumn{2}{|c|}{$\begin{array}{l}\text { miR-433 } \\
\text { expression }\end{array}$} & \multirow[b]{2}{*}{ P-value } \\
\hline & & Low & High & \\
\hline Age (years) & & & & 0.685 \\
\hline$<50$ & 26 & 14 & 12 & \\
\hline$\geq 50$ & 39 & 19 & 20 & \\
\hline Histology & & & & 0.526 \\
\hline $\mathrm{SCC}$ & 55 & 27 & 28 & \\
\hline Adenocarcinoma & 10 & 6 & 4 & \\
\hline HPV infection & & & & 0.247 \\
\hline Positive & 47 & 25 & 20 & \\
\hline Negative & 18 & 8 & 12 & \\
\hline Tumour size $(\mathrm{cm})$ & & & & 0.018 \\
\hline$<4$ & 29 & 10 & 19 & \\
\hline$\geq 4$ & 36 & 23 & 13 & \\
\hline $\begin{array}{l}\text { Family history } \\
\text { of cancer }\end{array}$ & & & & 0.163 \\
\hline No & 37 & 16 & 21 & \\
\hline Yes & 28 & 17 & 11 & \\
\hline FIGO stage & & & & 0.031 \\
\hline I-II & 24 & 8 & 16 & \\
\hline III-IV & 41 & 25 & 16 & \\
\hline $\begin{array}{l}\text { Lymph node } \\
\text { metastasis }\end{array}$ & & & & 0.001 \\
\hline Yes & 30 & 22 & 8 & \\
\hline No & 35 & 11 & 24 & \\
\hline Distant metastasis & & & & 0.032 \\
\hline Yes & 18 & 13 & 5 & \\
\hline No & 47 & 20 & 27 & \\
\hline
\end{tabular}

FIGO stage, International Federation of Gynecology and Obstetrics stage. SCC, squamous cell carcinoma.

Inc., Chicago, IL, USA). Student-Newman-Keuls (SNK) was used to compare differences between 2 groups in the multiple group study. $\mathrm{P}<0.05$ was considered to indicate a statistically significant result.

\section{Results}

miR-433 is frequently downregulated in cervical tissues and cell lines. In the present study, we first examined miR-433 expression in cervical cancer and corresponding adjacent normal tissues by RT-qPCR. Our results showed much higher miR-433 expression in the adjacent normal tissues than that observed in the cervical cancer tissues (Fig. 1A; $\mathrm{P}<0.05$ ). We then investigated the association between miR-433 and clinicopathological features in cervical cancer. The median miR-433 expression level (median=0.8902) was regarded as a cut-off to divide all cervical cancer patients into either the miR-433 low-expression group ( $\mathrm{n}=33$ ) or miR-433 highexpression group $(\mathrm{n}=32)$. As shown in Table II, low miR-433 expression level was significantly correlated with tumour size $(\mathrm{P}=0.018)$, FIGO stage $(\mathrm{P}=0.031)$, lymph node $(\mathrm{P}=0.001)$ and distant metastases $(\mathrm{P}=0.032)$. However, no significant correlations were noted between miR-433 expression and age $(\mathrm{P}=0.685)$, histology $(\mathrm{P}=0.526), \mathrm{HPV}$ infection $(\mathrm{P}=0.247)$ and family history of cancer $(\mathrm{P}=0.163)$.

We further measured expression levels of miR-433 in cervical cancer cell lines (HeLa, C-33A, SiHa and Ca-Ski) and human normal cervical epithelial cell line (Ect1/E6E7). As shown in Fig. 1B, the expression level of miR-433 was downregulated in cervical cancer cell lines compared with that noted in the Ect1/E6E7 cells $(\mathrm{P}<0.05)$.

Upregulation of miR-433 inhibits cell proliferation and invasion and promotes apoptosis in cervical cancer. Downregulation of miR-433 in cervical cancer prompted us to explore whether miR-433 acts as a tumour suppressor in cervical cancer. Therefore, we examined the effects of miR-433 overexpression on cervical cancer cells. HeLa and SiHa cells, which expressed relatively low miR-433 expression among the 4 examined cervical cancer cell lines, were transfected with miR-433 mimics or miR-NC. Expression levels determined through RT-qPCR confirmed marked upregulation of miR-433 in the HeLa and SiHa cells transfected with miR-433 mimics (Fig. 2A and B; P<0.05). Firstly, we measured cellular proliferation using MTT assay after transfection of HeLa and SiHa cells with miR-433 mimics or miR-NC. The results showed that restoration of the expression of miR-433 significantly decreased proliferation of the HeLa and $\mathrm{SiHa}$ cells compared with that noted in the miR-NC group (Fig. 2C and D; $\mathrm{P}<0.05)$. HeLa and SiHa cells were transfected with miR-433 mimics or miR-NC; and cell invasion assay was performed to evaluate the effects of miR-433 restoration on the invasion of these cells. Invasion capabilities of HeLa and $\mathrm{SiHa}$ cells were significantly suppressed when cells were transfected with the miR-433 mimics (Fig. 2E and F; P<0.05). Flow cytometric analysis was used to determine the apoptosis rates of the HeLa and SiHa cells transfected with the miR- 433 mimics or miR-NC. The results revealed that at $72 \mathrm{~h}$ after transfection, the apoptosis rate was significantly increased in the HeLa and $\mathrm{SiHa}$ cells transfected with miR-433 mimics compared with that noted in the miR-NC controls (Fig. $2 \mathrm{G}$ and $\mathrm{H} ; \mathrm{P}<0.05$ ). These results indicate that miR-433 acts as a tumour suppressor in cervical cancer.

$M T D H$ is a direct target gene of miR-433 in cervical cancer. To further elucidate the underlying mechanisms involved in the tumour-suppressive roles of miR-433 in cervical cancer cells, bioinformatic analysis was performed to search for potential downstream targets of miR-433. Hundreds of candidate targets were predicted, such as PAK4, PAX6, MACCI, MTDH, CREBI and Notch1. Among these candidate targets, $M T D H$ was selected for further target identification (Fig. 3A); this gene was found to be upregulated in cervical cancer tissues and to contribute to cervical cancer occurrence and progression $(27,28)$. We employed a luciferase reporter assay to ascertain whether $M T D H$ is a direct target gene of miR-433. HeLa and SiHa cells were cotransfected with pMIR-Report-MTDH-3'-UTR- 

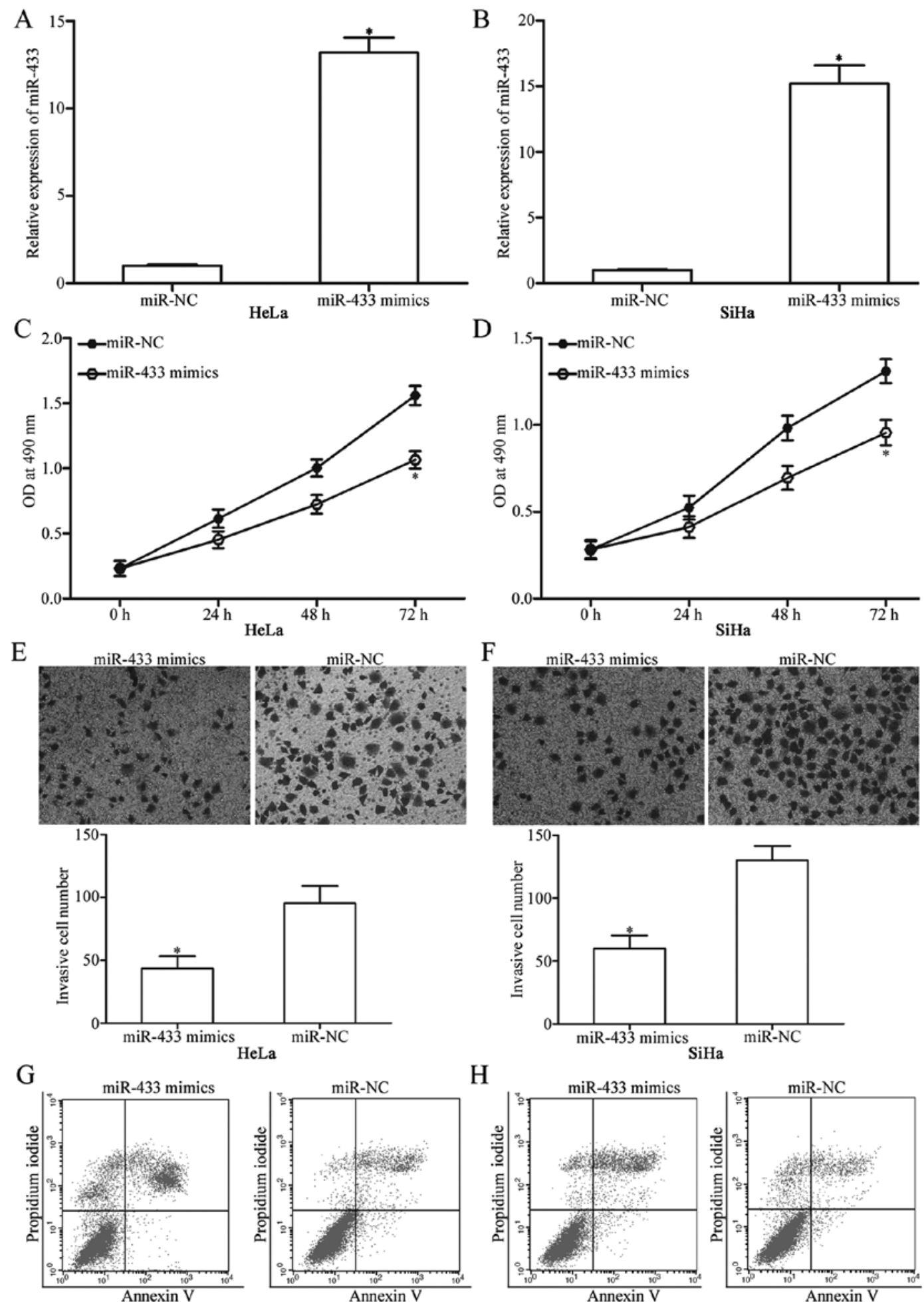

$\mathrm{H}$
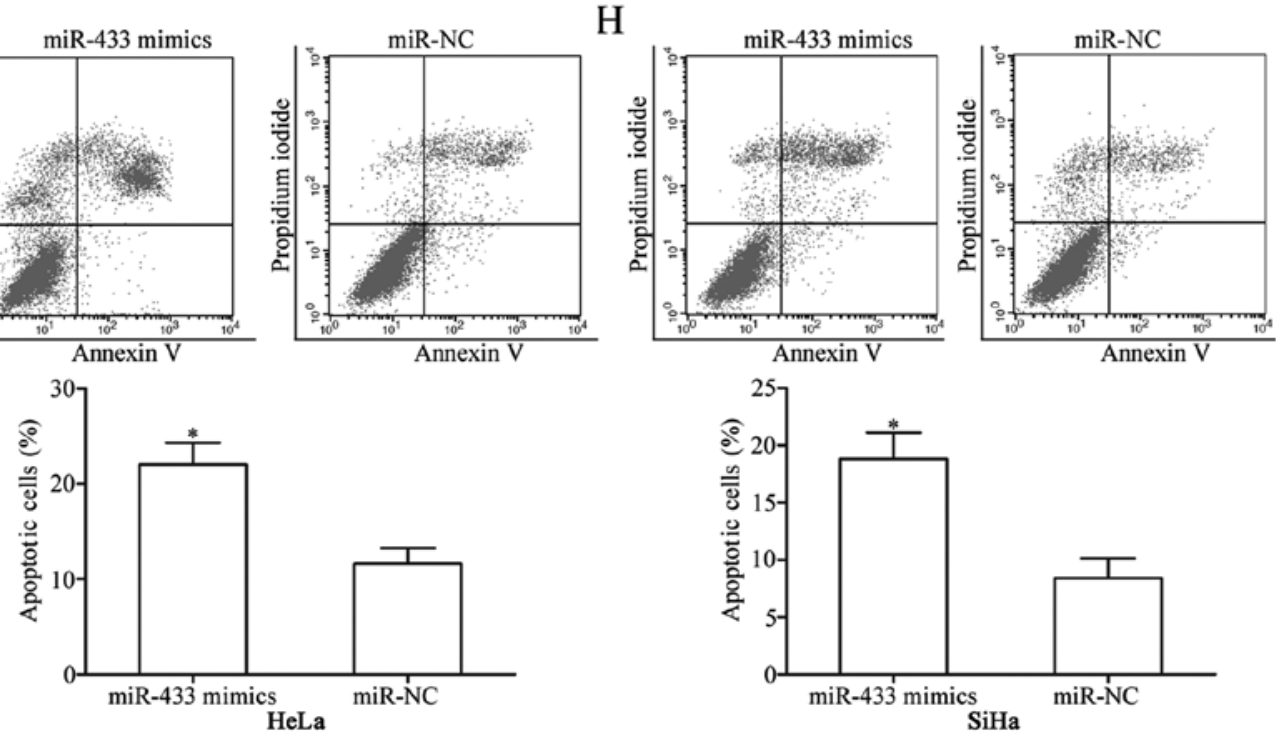

Figure 2. miR-433 reduces proliferation and invasion and increases apoptosis of HeLa and SiHa cells. HeLa and SiHa cells were transfected with miR-433 mimics or miR-NC. (A and B) After transfection, miR-433 expression was examined in the HeLa and SiHa cells through RT-qPCR. (C and D) Cell proliferation was assayed in HeLa and SiHa cells. (E and F) Results of cell invasion assay in the HeLa and SiHa cells. (G and H) Flow cytometric analysis was used to detect the apoptosis rate in the HeLa and SiHa cells; ${ }^{*} \mathrm{P}<0.05$ compared with miR-NC-transfected cells. 
A
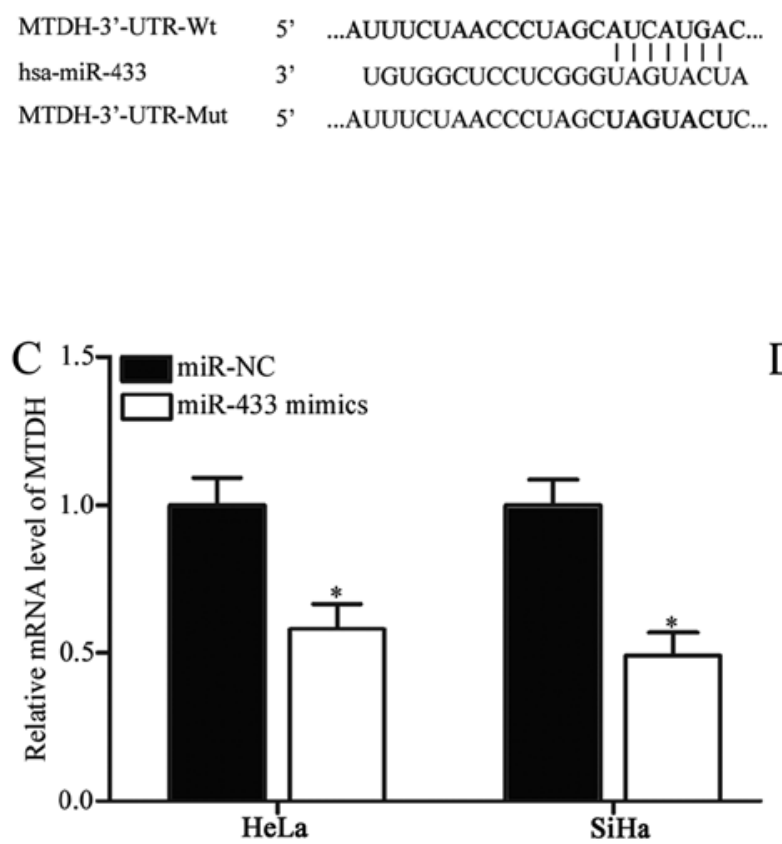

B

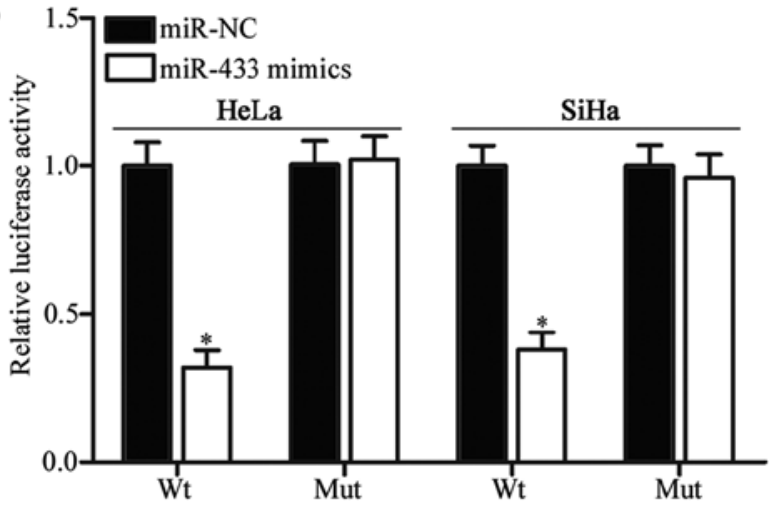

$\mathrm{D}$

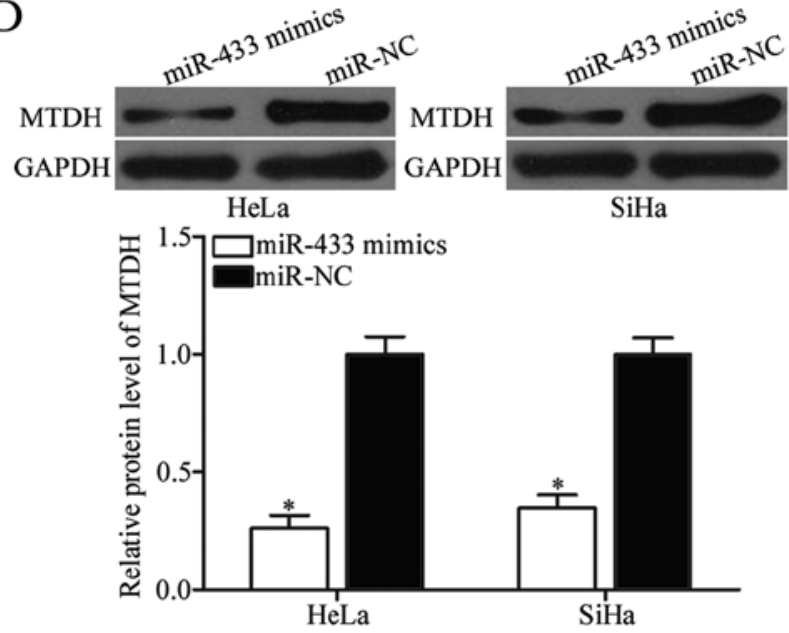

Figure 3. $M T D H$ is a direct target of miR-433 in cervical cancer. (A) Wild-type (Wt) and mutant (Mut) of putative miR-433 binding sequences in 3'-UTR of MTDH. (B) Measurement of luciferase activity in HeLa and SiHa cells cotransfected with pMIR-Report-MTDH-3'-UTR-Wt or pMIR-Report-MTDH-3'-UTRMut and miR-433 mimics or miR-NC. (C and D) Effects of miR-433 overexpression on endogenous MTDH mRNA and protein levels in HeLa and SiHa cells as assessed by RT-qPCR and western blotting, respectively; " $\mathrm{P}<0.05$ compared with the respective control.

wild-type (Wt) or pMIR-Report-MTDH-3'-UTR-mutant-type (Mut) and miR-433 mimics or miR-NC. The results showed that miR-433 introduction decreased luciferase activity of pMIR-Report-MTDH-3'-UTR-Wt, but not pMIR-ReportMTDH-3'-UTR-Mut (Fig. 3B; P<0.05).

We further investigated whether miR-433 overexpression can regulate MTDH expression in cervical cancer cells. Results of RT-qPCR and western blot analysis showed that ectopic expression of miR-433 in HeLa and SiHa cells significantly reduced MTDH expression at both mRNA and protein levels (Fig. 3C and D; $\mathrm{P}<0.05$ ). Collectively, these results suggest that $M T D H$ is a direct downstream target of miR-433 in cervical cancer.

MTDH expression is upregulated in cervical cancer tissues, and its expression is negatively correlated with $\mathrm{miR}-433$. To further explore the association between miR-433 and MTDH, MTDH expression was detected in cervical cancer and corresponding adjacent normal tissues. Data from RT-qPCR and western blot analysis demonstrated significantly increased expression of MTDH in cervical cancer tissues compared with that in corresponding adjacent normal tissues (Fig. 4A and B; $\mathrm{P}<0.05)$. We also evaluated the correlation between MTDH mRNA and miR-433 expression level in cervical cancer tissues and Spearman's correlation analysis indicated a significantly negative correlation between miR-433 and $M T D H$
mRNA expression among the cervical cancer tissues (Fig. 4C; $\mathrm{r}=-0.7038 ; \mathrm{P}<0.0001)$.

MTDH knockdown suppresses cervical cancer cell proliferation and invasion, and induces apoptosis in vitro. To investigate whether downregulation of MTDH expression exhibits tumour-suppressive functions similar to those of miR-433 overexpression in cervical cancer, HeLa and $\mathrm{SiHa}$ cells were transfected with si-MTDH to genetically knock down endogenous MTDH expression (Fig. 5A; P<0.05). Next, MTT assay, cell invasion assay and flow cytometric analysis were conducted in HeLa and SiHa cells transfected with si-MTDH or si-NC. The results showed that MTDH knockdown exhibited tumour-suppressive roles similar to those of miR-433 overexpression in cervical cancer cell proliferation (Fig. 5B and C; $\mathrm{P}<0,05$ ), invasion (Fig. 5D and $\mathrm{E} ; \mathrm{P}<0,05$ ) and apoptosis (Fig. 5F and $\mathrm{G} ; \mathrm{P}<0,05$ ) and further suggest that MTDH is a functional downstream target of miR-433 in cervical cancer.

Overexpression of MTDH reverses the tumour-suppressive effects of miR-433 in cervical cancer cells. To further evaluate whether MTDH mediates the effects of miR-433, which affects cervical cancer cell proliferation, invasion and apoptosis, rescue experiments were performed, and miR-433 mimics with or without pcDNA3.1-MTDH were transfected into HeLa 


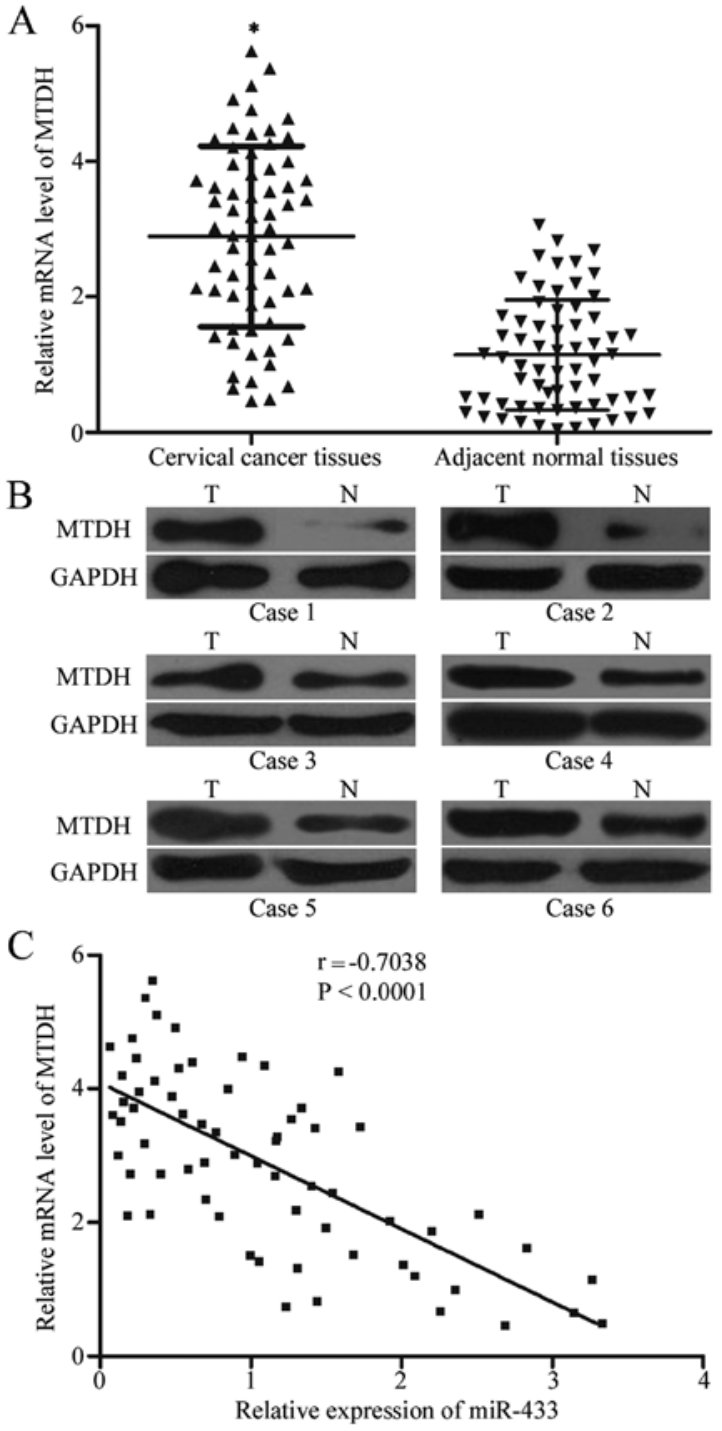

Figure 4. Expression levels of miR-433 and $M T D H$ mRNA are inversely correlated in cervical cancer tissues. (A and B) Expression of MTDH mRNA and protein was examined in cervical cancer tissues and corresponding adjacent normal tissues. (C) Negative correlation between $M T D H$ mRNA and miR-433 expression in cervical cancer tissues; ${ }^{*} \mathrm{P}<0.05$ compared with the respective control.

and SiHa cells. Western blot results confirmed that MTDH expression was recovered in the miR-433 mimic-transfected cells after being transfected with pcDNA3.1-MTDH (Fig. 6A; $\mathrm{P}<0.05)$. Rescue experiments revealed that MTDH overexpression markedly reversed the effects of miR- 433 overexpression in regards to proliferation (Fig. $6 \mathrm{~B}$ and $\mathrm{C} ; \mathrm{P}<0,05$ ), invasion (Fig. 6D and E; $\mathrm{P}<0,05$ ) and apoptosis (Fig. 6F and $\mathrm{G}$; $\mathrm{P}<0,05)$ of $\mathrm{HeLa}$ and $\mathrm{SiHa}$ cells. These results indicate that miR-433 exert its tumour-suppressing roles in cervical cancer cells, at least in part, by suppressing MTDH.

miR-433 inactivates the AKT and $\beta$-catenin signalling pathways in cervical cancer. MTDH was previously reported to play essential roles inthe regulation of the AKT and $\beta$-catenin pathways $(31,32)$. Thus, we detected expression levels of p-AKT, AKT, p- $\beta$-catenin and $\beta$-catenin in HeLa and SiHa cells after transfection with miR-433 mimics or miR-NC.
As shown in Fig. 7, restoration of expression of miR-433 decreased p-AKT and p- $\beta$-catenin expressions in the $\mathrm{HeLa}$ and $\mathrm{SiHa}$ cells. However, this restored expression did not affect total AKT and $\beta$-catenin expression. We also noted recovered expression levels of p-AKT and p- $\beta$-catenin in the miR-433 mimic-transfected HeLa and SiHa cells cotransfected with pcDNA3.1-MTDH. These results indicate that miR-433 exerts tumour-suppressing roles in cervical cancer cells by directly targeting MTDH and affecting downstream AKT and $\beta$-catenin pathways.

\section{Discussion}

Emerging data have shown that miRNAs play significant roles in various human cancers, including cervical cancer $(33,34)$. Aberrantly expressed miRNAs in cervical cancer contribute to tumour occurrence and development as either tumour suppressors or promoters (35). Therefore, identification of specific miRNAs and their targets in cervical cancer may provide novel and efficient therapeutic methods for patients with this malignancy. In the present study, we observed downregulation of miR-433 in cervical cancer tissues and cell lines compared with that in respective controls. Low miR-433 expression was significantly correlated with tumour size, FIGO stage, lymph node and distant metastases of patients with cervical cancer. miR-433 overexpression inhibited cell proliferation, and invasion and promoted apoptosis of cervical cancer. $M T D H$ was validated as a direct target of miR-433 in cervical cancer. Therefore, our data indicate that miR-433 may be associated with progression of cervical cancer malignancy.

Numerous studies have reported abnormal expression of miR-433 in certain types of human cancer. For example, miR-433 was found to be significantly downregulated in gastric cancer tissues. Aberrant expression of miR-433 was correlated with pM and pTNM stage in clinical gastric cancer patients (36). In colorectal cancer, miR-433 expression was lower in tumour tissues and cell lines compared with that in corresponding adjacent tissues and normal human colon mucosal epithelial cell line. Low expression level of miR-433 was associated with tumour size in patients with colorectal cancer (37). Downregulation of miR-433 was also observed in glioma (24), retinoblastoma (25), ovarian cancer (26), hepatocellular (38) and oral squamous cell carcinoma (39). These findings suggest that miR-433 may be a diagnostic and prognostic biomarker for a number of cancer types.

miR-433 was reported to play important roles in the formation and progression of various types of human cancer. For example, Guo et al discovered that upregulation of miR-433 suppressed cell proliferation, migration, invasion and cell cycle progression of gastric cancer (36). In colorectal cancer, overexpression of miR-433 decreased cell viability and increased apoptosis (37). Sun et al reported that miR-433 overexpression suppressed glioma cell proliferation and metastasis, induced apoptosis in vitro and reduced tumour growth in vivo (24). A previous functional study demonstrated that restoration of miR-433 expression attenuated retinoblastoma cell proliferation and motility and promoted cell cycle arrest and apoptosis (25). In ovarian cancer, ectopic expression of miR-433 suppressed cell migration and invasion (26). In hepatocellular carcinoma, 


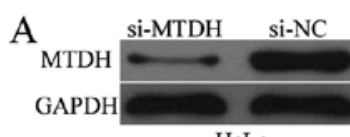

HeLa

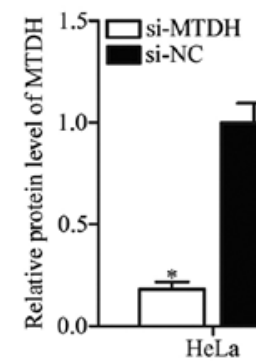

B

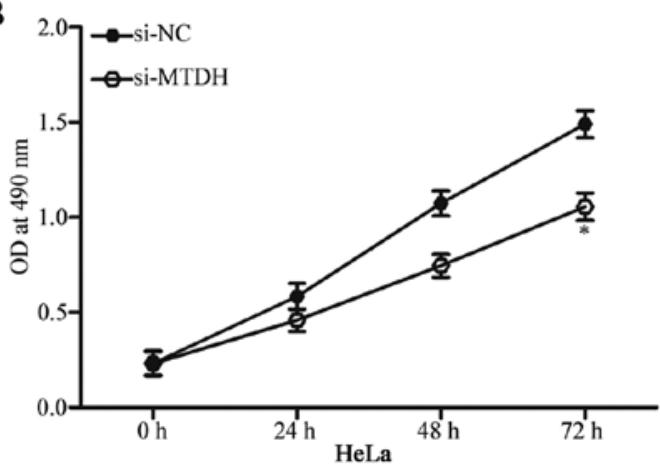

D
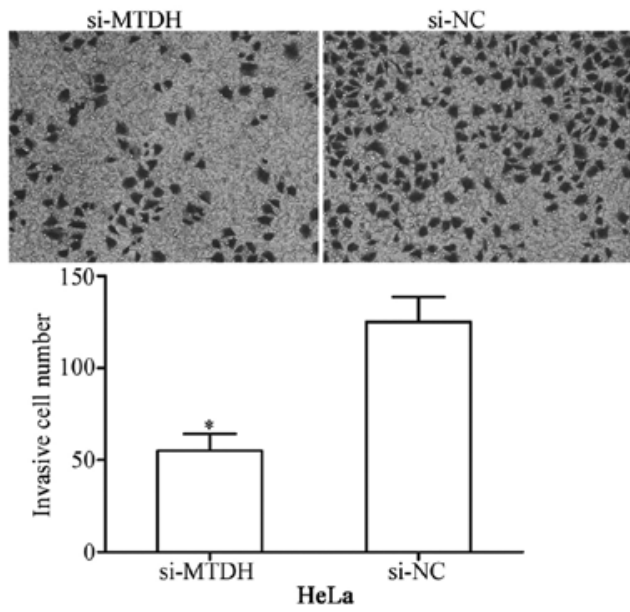

F
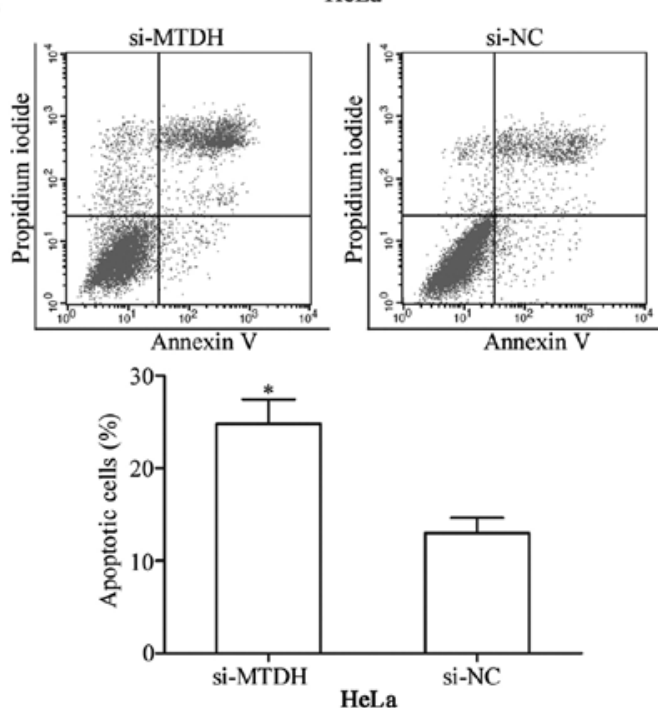

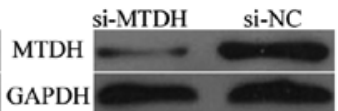

$\mathrm{SiHa}$

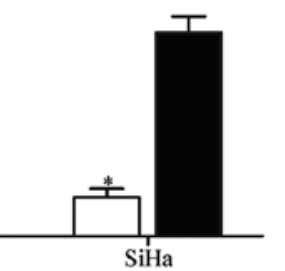

C

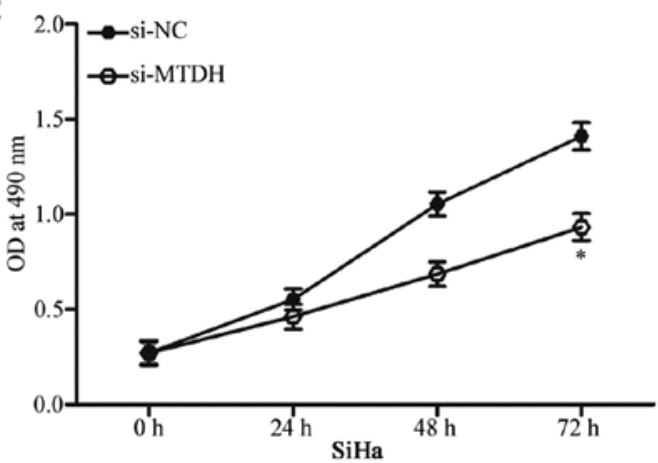

E
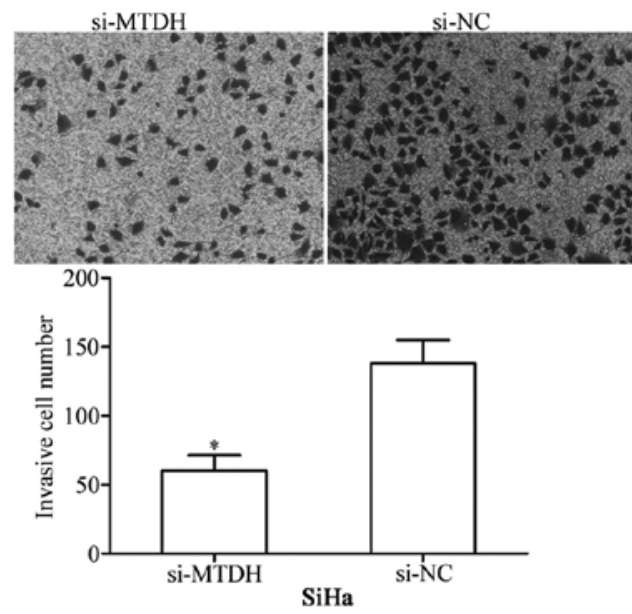

G
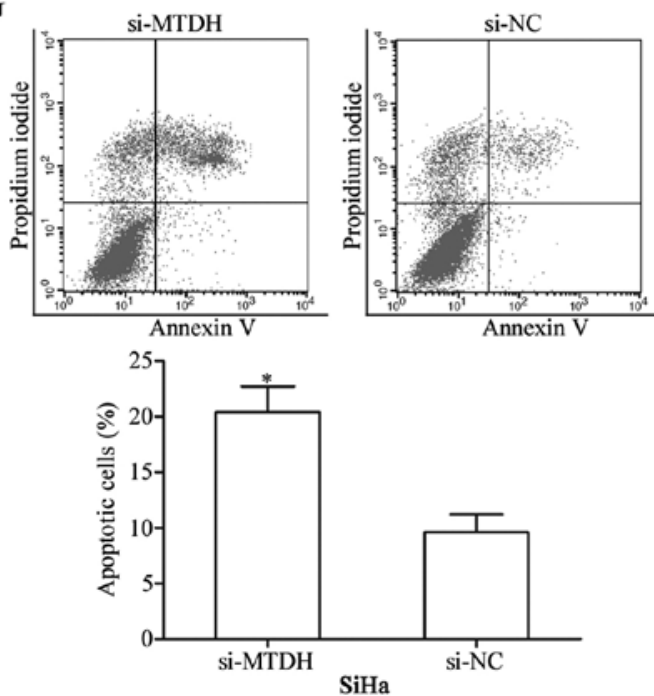

Figure 5. MTDH downregulation suppresses proliferation and invasion and promotes apoptosis of HeLa and SiHa cells. (A) HeLa and SiHa cells were transfected with si-MTDH or si-NC. After transfection for $72 \mathrm{~h}, \mathrm{MTDH}$ protein expression in HeLa and SiHa cells was determined using western blot analysis. (B and C) MTT assay was performed to evaluate cell proliferation of the HeLa and SiHa cells transfected with si-MTDH or si-NC. (D and E) Cell invasion assay was performed to assess the effect of MTDH knockdown on invasion of HeLa and SiHa cells. (F and G) Flow cytometric analysis was used to measure the apoptotic rate of HeLa and SiHa cells transfected with si-MTDH or si-NC; ${ }^{*} \mathrm{P}<0.05$ compared with the respective control. 
A

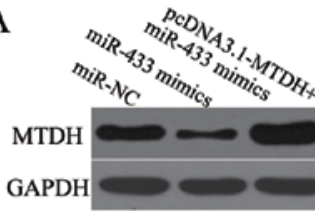

HeLa

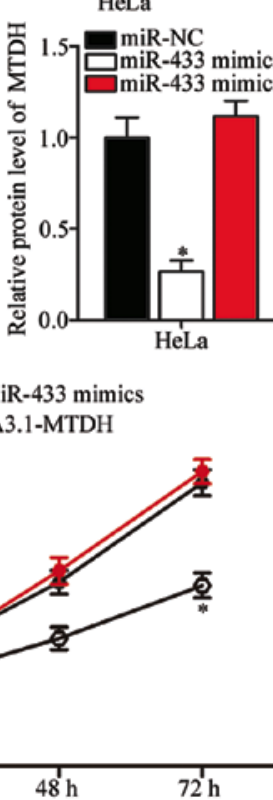

D
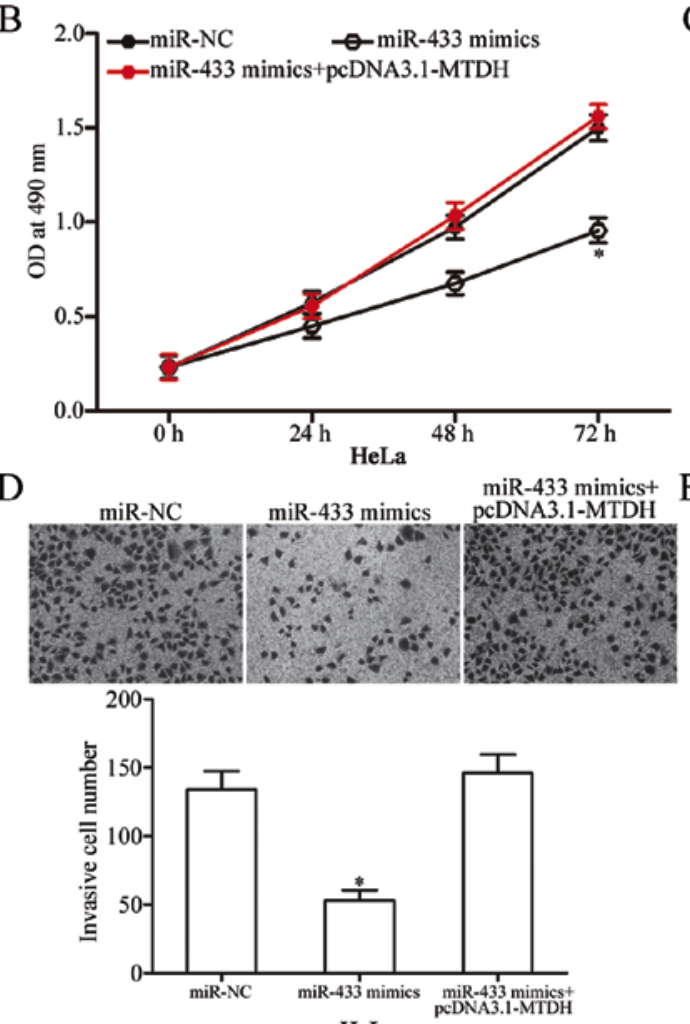

HeLa

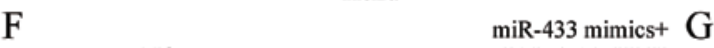

F $\quad$ miR-433 mimicst $\mathrm{G}$
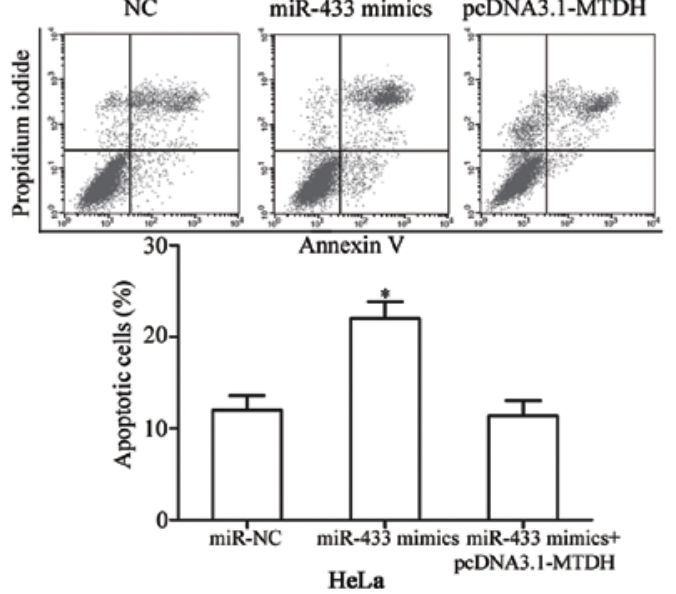

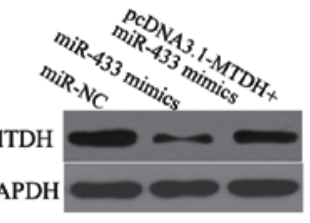

$\mathrm{SiHa}$

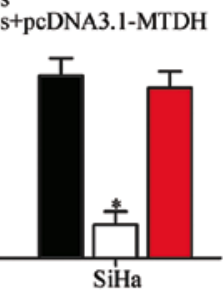

C

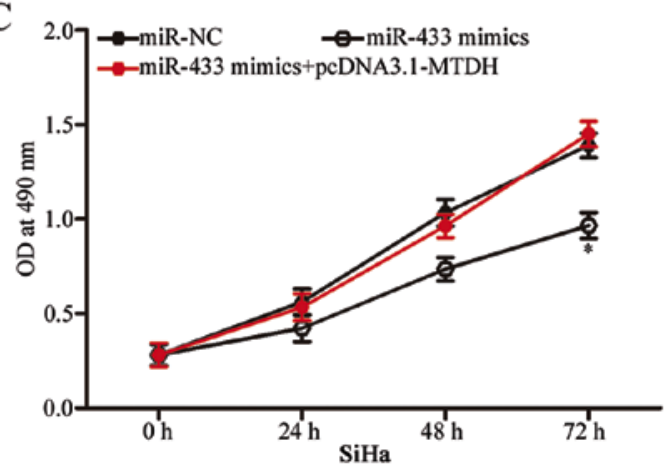

miR-433 mimics+
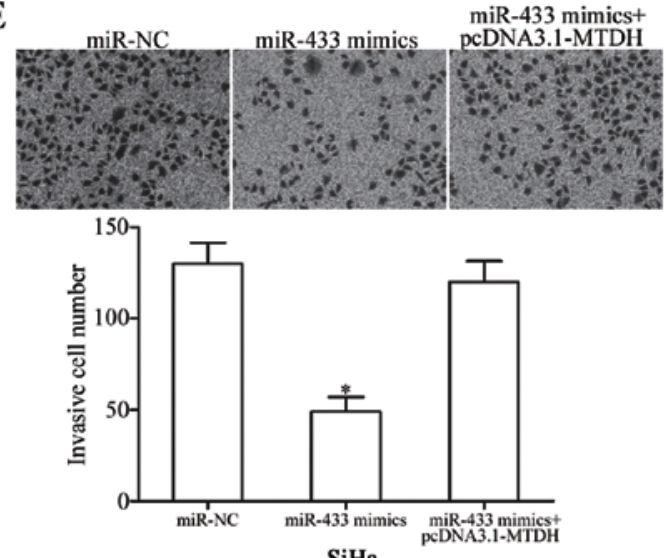

$\mathrm{SiHa}$
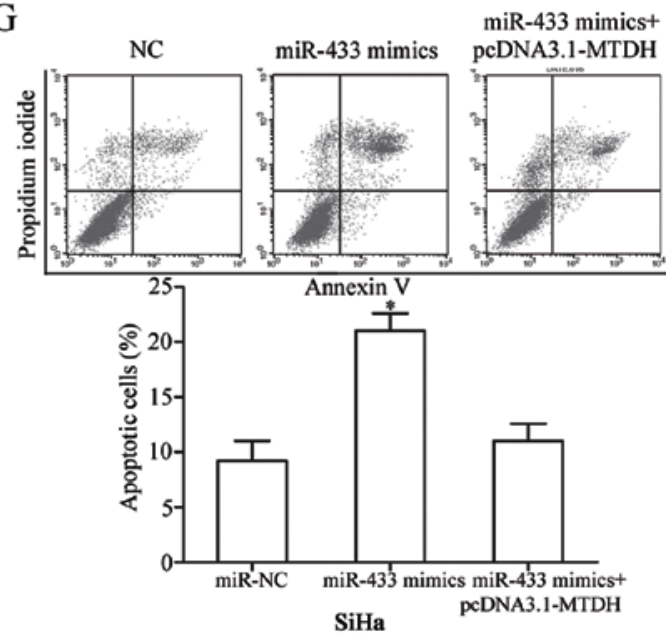

Figure 6. Restoration expression of MTDH rescued miR-433-induced tumour-suppressive effects on behaviours of cervical cancer cell. (A) Western blot analysis was performed to detect MTDH expression in HeLa and SiHa cells transfected with miR-NC, miR-433 mimics or miR-433 mimics + pcDNA3.1-MTDH. (B and C) MTT assay was used to detect proliferation in HeLa and SiHa cells transfected with miR-NC, miR-433 mimics or miR-433 mimics + pcDNA3.1MTDH. (D and E) Cell invasion assay of HeLa and SiHa cells transfected with miR-NC, miR-433 mimics or miR-433 mimics + pcDNA3.1-MTDH. (F and G) Flow cytometric analysis of HeLa and SiHa transfected with miR-NC, miR-433 mimics or miR-433 mimics + pcDNA3.1-MTDH; ${ }^{*}<0.05$ compared with the respective control. 


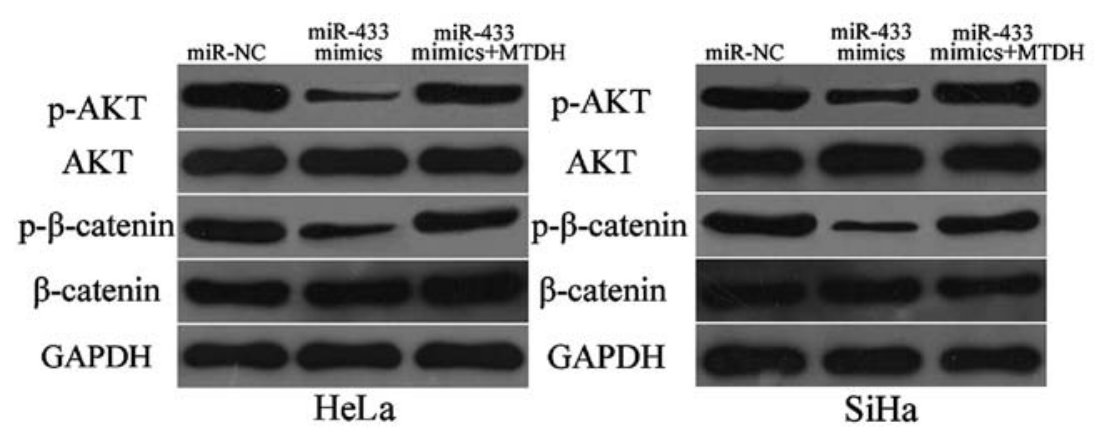

Figure 7. Upregulation of miR-433 inactivates AKT and $\beta$-catenin signalling pathways in HeLa and SiHa cells. Western blot analysis of p-AKT, AKT, p- $\beta$ catenin and $\beta$-catenin expression in HeLa and SiHa cells transfected with miR-NC, miR-433 mimics and miR-433 mimics + pcDNA3.1-MTDH.

restoration of miR-433 expression reduced cell proliferation and migration $(38,40)$. Wang et al revealed that restoration of miR-433 expression inhibited cell proliferation and motility in oral squamous cell carcinoma (39). These findings also suggest that miR-433 may perform important functions in these types of cancer and may be investigated as a potential therapeutic target for the treatment of various types of cancer.

Identification of cancer-specific miRNAs and their target genes is important for elucidating miRNA functions in tumourigenesis and tumour development and may provide promising therapeutic targets (41). Several miR-433 targets were identified; such targets include KRAS in gastric cancer (36), MACC1 in colorectal cancer (37), cAMP responsive element binding protein (CREB) in glioma (24), Notch1 and PAX6 in retinoblastoma (25), Notch1 in ovarian cancer (26), PAK4 and CREB1 in hepatocellular carcinoma $(38,40)$, and histone deacetylase 6 in oral squamous cell carcinoma (39). In the present study, MTDH was predicted as a potential target of miR-433 using bioinformatic analysis. Subsequently, luciferase reporter assays indicated direct binding of miR-433 to MTDH 3'-UTR. RT-qPCR and western blot analysis revealed that miR-433 negatively regulates MTDH expression at both the mRNA and protein levels in cervical cancer cells. Our experimental data further revealed a significant increase in MTDH in cervical cancer tissues, and this result was negatively correlated with miR-433 expression patterns. MTDH knockdown showed tumour-suppressive roles similar to those as miR-433 overexpression in cervical cancer. Finally, rescue experiments revealed that MTDH upregulation markedly reversed the effects of miR-433 overexpression on cervical cancer cells. These results strongly demonstrated that MTDH is a direct target of miR-433 in cervical cancer.

MTDH gene is located at chromosome $8 \mathrm{q} 22$, and it was first discovered in human foetal astrocytes by $\mathrm{Su}$ et al in 2002 (42). $M T D H$ encodes for a 582-amino acid protein and is ubiquitously expressed in all organs and distributed in the cell cytoplasm, membrane, nucleus and endoplasmic reticulum (43). Previous studies have reported that MTDH is overexpressed in a variety of human cancers, such as non-small-cell lung (44), gastric (45), breast (46), ovarian (47) and bladder cancer (48). MTDH plays critical roles in multiple biological processes in tumourigenesis and tumour development through integration of oncogenic pathways, including PI3K/AKT, nuclear factor- $\kappa \mathrm{B}$, mitogen-activated protein kinase and $\mathrm{Wnt} / \beta$-catenin signalling pathways (49-51). In cervical cancer, MTDH is upregulated and is significantly correlated with tumour size, lymph node metastasis, TNM stage and tumour differentiation $(27,28)$. Univariate and multivariate analyses indicated a shortened survival period of cervical cancer patients with high expression levels of MTDH (28). Therefore, MTDH is considered a valuable prognostic marker and therapeutic target for several types of cancer.

In conclusion, the present study demonstrated that miR-433 is significantly downregulated in cervical cancer, and low expression level of this miRNA is associated with tumour size, FIGO stage, lymph node and distant metastases. In vitro studies demonstrated that miR-433 suppressed cellular proliferation and invasion and increased apoptosis in cervical cancer cells. Mechanistically, $M T D H$ was validated as a direct target gene of miR-433 in cervical cancer. miR-433 may be a novel target for future cervical cancer therapy. In subsequent research, we may analyze the connection of miR-433 with AKT and $\beta$-catenin in patient samples, and the regulatory roles of miR-433 on other signalling pathways.

\section{Acknowledgements}

The study was supported by grants from Guangdong Province Science and Technology Pan Projects (nos. 2013B021800137, 2013B022000044 and 2016A020215074) and Guangdong Province Medical Research Foundation (no. A2016060).

\section{References}

1. Jemal A, Bray F, Center MM, Ferlay J, Ward E and Forman D: Global cancer statistics. CA Cancer J Clin 61: 69-90, 2011.

2. Sankaranarayanan R: Overview of cervical cancer in the developing world. FIGO 26th Annual Report on the Results of Treatment in Gynecological Cancer. Int J Gynaecol Obstet 95 (Suppl 1): S205-S210, 2006.

3. Cuzick J, Bergeron C, von Knebel Doeberitz M, Gravitt P, Jeronimo J, Lorincz AT, J L M Meijer C, Sankaranarayanan R, JF Snijders P and Szarewski A: New technologies and procedures for cervical cancer screening. Vaccine 30 (Suppl 5): F107-F116, 2012.

4. Crafton SM and Salani R: Beyond chemotherapy: An overview and review of targeted therapy in cervical cancer. Clin Ther 38: 449-458, 2016.

5. Kokka F, Bryant A, Brockbank E, Powell M and Oram D: Hysterectomy with radiotherapy or chemotherapy or both for women with locally advanced cervical cancer. Cochrane Database Syst Rev 4: CD010260, 2015.

6. de Freitas AC, Gomes Leitão MC and Coimbra EC: Prospects of molecularly-targeted therapies for cervical cancer treatment. Curr Drug Targets 16: 77-91, 2015. 
7. Dai S, Lu Y, Long Y, Lai Y, Du P, Ding N and Yao D: Prognostic value of microRNAs in cervical carcinoma: A systematic review and meta-analysis. Oncotarget 7: 35369-35378, 2016.

8. Fan JY, Fan YJ, Wang XL, Gao HJ, Zhang Y, Liu M and Tang H: miR-429 is involved in regulation of NF- $\mathrm{KB}$ activity by targeting IKK $\beta$ and suppresses oncogenic activity in cervical cancer cells. FEBS Lett 591: 118-128, 2017.

9. Yan S, Li X, Jin Q and Yuan J: MicroRNA-145 sensitizes cervical cancer cells to low-dose irradiation by downregulating OCT4 expression. Exp Ther Med 12: 3130-3136, 2016.

10. Sun P, Shen Y, Gong JM, Zhou LL, Sheng JH and Duan FJ: A new microRNA expression signature for cervical cancer. Int J Gynecol Cancer 27: 339-343, 2017.

11. Brodersen P and Voinnet O: Revisiting the principles of microRNA target recognition and mode of action. Nat Rev Mol Cell Biol 10: 141-148, 2009.

12. Harries LW: Long non-coding RNAs and human disease. Biochem Soc Trans 40: 902-906, 2012.

13. Bartel DP: MicroRNAs: Genomics, biogenesis, mechanism, and function. Cell 116: 281-297, 2004.

14. Hong Y, Liang H, Uzair-Ur-Rehman, Wang Y, Zhang W, Zhou Y, Chen S, Yu M, Cui S, Liu M, et al: miR-96 promotes cell proliferation, migration and invasion by targeting PTPN9 in breast cancer. Sci Rep 6: 37421, 2016.

15. Liu Y, Hu X, Xia D and Zhang S: MicroRNA-181b is downregulated in non-small cell lung cancer and inhibits cell motility by directly targeting HMGB1. Oncol Lett 12: 4181-4186, 2016.

16. Bucay N, Sekhon K, Yang T, Majid S, Shahryari V, Hsieh C, Mitsui Y, Deng G, Tabatabai ZL, Yamamura S, et al MicroRNA-383 located in frequently deleted chromosomal locus 8p22 regulates CD44 in prostate cancer. Oncogene 36: 2667-2679, 2017.

17. Lai XJ, Cheng XY and Hu LD: microRNA 421 induces apoptosis of c-33a cervical cancer cells via down-regulation of Bcl-xL. Genet Mol Res 15: 15, 2016.

18. Li X, Chen W, Zeng W, Wan C, Duan S and Jiang S: microRNA-137 promotes apoptosis in ovarian cancer cells via the regulation of XIAP. Br J Cancer 116: 66-76, 2017.

19. Wang J, Liu H, Tian L, Wang F, Han L, Zhang W and Bai YA miR-15b inhibits the progression of glioblastoma cells through targeting insulin-like growth factor receptor 1 . Horm Cancer 8: 49-57, 2017.

20. Li Y, Jiang W, Hu Y, Da Z, Zeng C, Tu M, Deng Z and Xiao W: MicroRNA-199a-5p inhibits cisplatin-induced drug resistance via inhibition of autophagy in osteosarcoma cells. Oncol Lett 12 4203-4208, 2016.

21. Wang P, Deng Y and Fu X: MiR-509-5p suppresses the proliferation, migration, and invasion of non-small cell lung cancer by targeting YWHAG. Biochem Biophys Res Commun, 2016.

22. Hwang HW and Mendell JT: MicroRNAs in cell proliferation, cell death, and tumorigenesis. Br J Cancer 96 (Suppl): R40-R44, 2007.

23. Calin GA and Croce CM: MicroRNA signatures in human cancers. Nat Rev Cancer 6: 857-866, 2006.

24. Sun S, Wang X, Xu X, Di H, Du J, Xu B, Wang Q and Wang J: MiR-433-3p suppresses cell growth and enhances chemosensitivity by targeting CREB in human glioma. Oncotarget 8 : $5057-5068,2017$

25. Li X, Yang L, Shuai T, Piao T and Wang R: MiR-433 inhibits retinoblastoma malignancy by suppressing Notch1 and PAX6 expression. Biomed Pharmacother 82: 247-255, 2016.

26. Liang T, Guo Q, Li L, Cheng Y, Ren C and Zhang G: MicroRNA-433 inhibits migration and invasion of ovarian cancer cells via targeting Notch1. Neoplasma 63: 696-704, 2016.

27. Long M, Dong K, Gao P, Wang X, Liu L, Yang S, Lin F, Wei J and Zhang H: Overexpression of astrocyte-elevated gene-1 is associated with cervical carcinoma progression and angiogenesis. Oncol Rep 30: 1414-1422, 2013.

28. Huang K, Li LA, Meng Y, You Y, Fu X and Song L: High expression of astrocyte elevated gene-1 (AEG-1) is associated with progression of cervical intraepithelial neoplasia and unfavorable prognosis in cervical cancer. World J Surg Oncol 11: 297, 2013

29. Livak KJ and Schmittgen TD: Analysis of relative gene expression data using real-time quantitative PCR and the $2^{-\Delta \Delta C T}$ method. Methods 25: 402-408, 2001.
30. Lewis BP, Burge CB and Bartel DP: Conserved seed pairing, often flanked by adenosines, indicates that thousands of human genes are microRNA targets. Cell 120: 15-20, 2005.

31. Li WF, Dai H, Ou Q, Zuo GQ and Liu CA: Overexpression of microRNA-30a-5p inhibits liver cancer cell proliferation and induces apoptosis by targeting MTDH/PTEN/AKT pathway. Tumour Biol 37: 5885-5895, 2016.

32. Shen X, Si Y, Yang Z, Wang Q, Yuan J and Zhang X: MicroRNA542-3p suppresses cell growth of gastric cancer cells via targeting oncogene astrocyte-elevated gene-1. Med Oncol 32: 361, 2015.

33. Hu X, Schwarz JK, Lewis JS Jr, Huettner PC, Rader JS, Deasy JO, Grigsby PW and Wang X: A microRNA expression signature for cervical cancer prognosis. Cancer Res 70: 1441-1448, 2010.

34. Lee JW, Choi CH, Choi JJ, Park YA, Kim SJ, Hwang SY, Kim WY, Kim TJ, Lee JH, Kim BG, et al: Altered microRNA expression in cervical carcinomas. Clin Cancer Res 14: 2535-2542, 2008.

35. Esquela-Kerscher A and Slack FJ: Oncomirs - microRNAs with a role in cancer. Nat Rev Cancer 6: 259-269, 2006.

36. Guo LH, Li H, Wang F, Yu J and He JS: The tumor suppressor roles of miR-433 and miR-127 in gastric cancer. Int J Mol Sci 14: 14171-14184, 2013

37. Li J, Mao X, Wang X, Miao G and Li J: miR-433 reduces cell viability and promotes cell apoptosis by regulating MACC1 in colorectal cancer. Oncol Lett 13: 81-88, 2017.

38. Xue J, Chen LZ, Li ZZ, Hu YY, Yan SP and Liu LY: MicroRNA-433 inhibits cell proliferation in hepatocellular carcinoma by targeting p21 activated kinase (PAK4). Mol Cell Biochem 399: 77-86, 2015.

39. Wang XC, Ma Y, Meng PS, Han JL, Yu HY and Bi LJ: miR-433 inhibits oral squamous cell carcinoma (OSCC) cell growth and metastasis by targeting HDAC6. Oral Oncol 51: 674-682, 2015.

40. Yang Z, Tsuchiya H, Zhang Y, Hartnett ME and Wang L: MicroRNA-433 inhibits liver cancer cell migration by repressing the protein expression and function of cAMP response elementbinding protein. J Biol Chem 288: 28893-28899, 2013

41. Chen X, Bo L, Lu W, Zhou G and Chen Q: MicroRNA-148b targets Rho-associated protein kinase 1 to inhibit cell proliferation, migration and invasion in hepatocellular carcinoma. Mol Med Rep 13: 477-482, 2016

42. Su ZZ, Kang DC, Chen Y, Pekarskaya O, Chao W, Volsky DJ and Fisher PB: Identification and cloning of human astrocyte genes displaying elevated expression after infection with HIV-1 or exposure to HIV-1 envelope glycoprotein by rapid subtraction hybridization, RaSH. Oncogene 21: 3592-3602, 2002.

43. Lee SG, Kang DC, DeSalle R, Sarkar D and Fisher PB: AEG-1/MTDH/LYRIC, the beginning: Initial cloning, structure, expression profile, and regulation of expression. Adv Cancer Res 120: 1-38, 2013.

44. Ke ZF, Mao X, Zeng C, He S, Li S and Wang LT: AEG-1 expression characteristics in human non-small cell lung cancer and its relationship with apoptosis. Med Oncol 30: 383, 2013.

45. Dong L, Qin S, Li Y, Zhao L, Dong S, Wang Y, Zhang C and Han S: High expression of astrocyte elevated gene-1 is associated with clinical staging, metastasis, and unfavorable prognosis in gastric carcinoma. Tumour Biol 36: 2169-2178, 2015.

46. Tokunaga E, Nakashima Y, Yamashita N, Hisamatsu Y, Okada S, Akiyoshi S, Aishima S, Kitao H, Morita M and Maehara Y: Overexpression of metadherin/MTDH is associated with an aggressive phenotype and a poor prognosis in invasive breast cancer. Breast Cancer 21: 341-349, 2014.

47. Zhou B, Yang J, Shu B, Liu K, Xue L, Su N, Liu J and Xi T: Overexpression of astrocyte-elevated gene-1 is associated with ovarian cancer development and progression. Mol Med Rep 11: 2981-2990, 2015

48. Zhou J, Li J, Wang Z, Yin C and Zhang W: Metadherin is a novel prognostic marker for bladder cancer progression and overall patient survival. Asia Pac J Clin Oncol 8: e42-e48, 2012.

49. Ge X, Lv X, Feng L, Liu X, Gao J, Chen N and Wang X: Metadherin contributes to the pathogenesis of diffuse large B-cell lymphoma. PLoS One 7: e39449, 2012.

50. Zhang J, Zhang Y, Liu S, Zhang Q, Wang Y, Tong L, Chen X, Ji Y, Shang Q, Xu B, et al: Metadherin confers chemoresistance of cervical cancer cells by inducing autophagy and activating ERK/NF-кB pathway. Tumour Biol 34: 2433-2440, 2013.

51. Hu G, Wei Y and Kang Y: The multifaceted role of MTDH/AEG-1 in cancer progression. Clin Cancer Res 15: 5615-5620, 2009. 